\title{
More Harmonies of Scriabine
}

Author(s): G. H. Clutsam

Source: The Musical Times, Vol. 54, No. 845 (Jul. 1, 1913), pp. 441-443

Published by: Musical Times Publications Ltd.

Stable URL: http://www.jstor.org/stable/906336

Accessed: 20-06-2016 07:42 UTC

Your use of the JSTOR archive indicates your acceptance of the Terms \& Conditions of Use, available at

http://about.jstor.org/terms

JSTOR is a not-for-profit service that helps scholars, researchers, and students discover, use, and build upon a wide range of content in a trusted digital archive. We use information technology and tools to increase productivity and facilitate new forms of scholarship. For more information about JSTOR, please contact support@jstor.org.

Musical Times Publications Ltd. is collaborating with JSTOR to digitize, preserve and extend access to The Musical Times 
one cannot doubt any longer that it fulfils all the conditions required, according to that definition, from the true work of art.

It also affords an argument in favour of the opinion that programme-music, \&c., should be judged exactly as pure music, and by the same standards. If a work does not contain its own message wholly and unconditionally, if the connections between all its parts are not independent and satisfactory in themselves, that work remains imperfect, and nothing can mend it. If it is satisfactory, any other pleasure derived from it can no more be considered as correlative to the artistic pleasure proper than can be added; for instance, an inch and an ounce: they are altogether different and incompatible things.

To conclude in Wagner's own words, music has been fertilized by poetry, which gave it a new stimulus after the exhaustion of the resources afforded by formal symmetries derived from 'dance and march.' And it is only as stimuli that programmatic elements should be taken into account. It is vain to seek in what measure the descriptive themes in Liszt's or M. Ravel's 'Jeux d'eau' help the hearers to evoke the actual play of waters, or the sequence of episodes in Balakirev's 'Tamara,' the story of the beautiful and wanton Caucasian queen. Once the music is written, the programme has served its turn; if the hearer feels in need of it, the fault lies with him, or with the composer, but certainly not with the principle of poetic music.

\section{MORE HARMONIES OF SCRIABINE.}

\section{By G. H. Clutsam.}

In my article on 'The harmonies of Scriabine,' in the March number of the Musical Times, which was particularly concerned with the contents of his symphonic-poem, 'Prometheus,' I endeavoured to show how the composer had drawn all his material from the series of notes that are formed from the vibratory impulse of any fundamental tone. Theoretically, of course, in this series we have been presented with a natural scale that has had several of its rough edges refined in the process of making it practical and pleasant to the ear. The value of its intervals has been proportioned to something approaching an equable distribution for harmonic purposes, and it would be preferable, in a rough glance at the latest harmonic innovations offered by Scriabine in his recent Pianoforte sonatas (the sixth and seventh, Opp. 62 and 64 ), to accept this distribution with its recognized variants as a basis for analysis, rather than become involved in the complexities attached to the consideration of an awkward scale succession.

In any case, this scale succession inevitably produces a chord with dominant tendencies, comprehending variants of the accepted ninth, eleventh, and thirteenth combinations, and Scriabine's most recent innovations can easily be understood as an explanation of its cumulative possibilities.
The essential difference between the harmonies on which 'Prometheus' is founded and the sixth Sonata is slight. In the first case, the basic chord is :

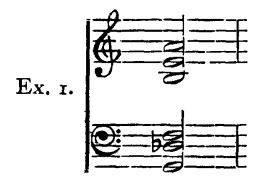

a chord of the dominant thirteenth with major ninth and flattened fifth.

In the other :

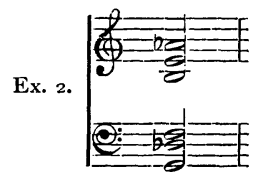

-the same chord, with minor ninth; and the scale on which the melodic line is constructed, with the same fundamental, is :

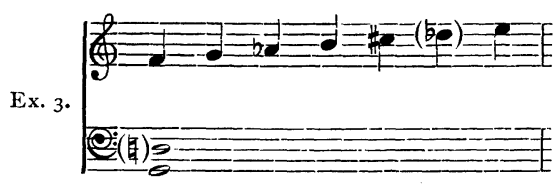

the difference between this and an ordinary diatonic scale being, of course, that all the intervals can, like the whole-tone scale, be assimilated in a complete chord, dominant in all its tendencies. In Scriabine's fifth Sonata, Op. 53, there are many tentative examples of the interesting harmonies that provide not only the foundation but the entire structure of his two later works in the same form, and although from beginning to end there is no definite assertion of a tonic chord (the nearest approach is in the principal subject) :

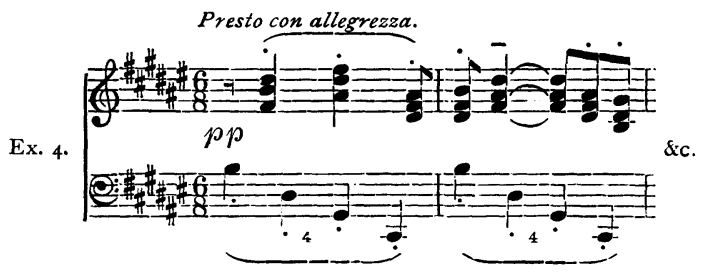

there is always the suggestion of a decided tonality. It might be here pointed out that throughout this experimental work, all chords that might serve as points of rest, i.e., exercising the functions of the ordinary tonic triad, take that recognised form with the addition of an added sixth or seventh :

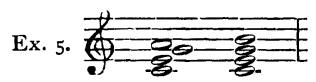

The quasi-cadenza in the introduction, with which the work also concludes, emphasises the idea in no uncertain fashion : 


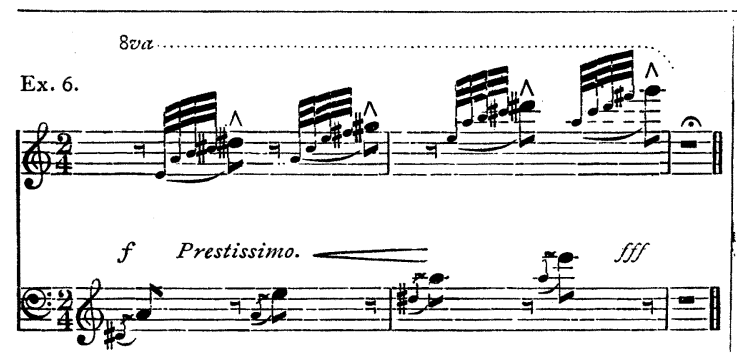

But in the works that I propose to consider, even this slight offering to a convention that has been the essential of all music that has counted in the past is deliberately withheld. It is not difficult to appreciate the fact that a definite tonality is always present, but it is asserted entirely by the aid of the extended dominant, unresolved.

The old text-books are generally emphatic in the statement that, above all, the functions of the dominant chord, seventh, ninth, thirteenth, or whatever shape or form it took, were primarily concerned in the establishment of a tonality, but for plausible æsthetic considerations, insisted on its resolution. It is logical to presume that if the influence of the dominant alone is sufficiently potent in its suggestion to fix a tonality on the mind, a resolution proper is actually superfluous. Many composers have recognised the æsthetic import of leaving the resolution in the air, and the earliest to carry it into practice, with elaborate significance that brought upon him the derision of his academic and theoretical contemporaries, was Wagner.

The opening of the 'Tristan' Prelude might be cited as an example of a sequence that suggests a peaceful wandering through half-a-dozen tonalities by means of dominants for twenty bars, when one, in a half-hearted fashion enough, ultinıately decides to acknowledge its family. Much water has run down the musical Thames, of course, since Wagner ventured on his innovations in this respect, and his experiments have already entered the regions of the primitive.

If familiarity has justified Wagner, there is every reason to suppose that the passage of time will justify Scriabine, who has many other qualities, besides his curious harmonic methods, to recommend him to the public. Briefly, although they are not concerned with the subject of this article, they convey a superb sense of form, a fine rhythmical force, and a magnificent power of finding in his slender material all those contrasting moods and emotions that go to the making-up of a satisfactory work of art. His technical expression is so sure, that there can be no question of his experiments existing for themselves alone. $\mathrm{He}$ undoubtedly thinks in his medium, and his thought is of such fine quality that the little trouble involved in understanding his language is soon and amply repaid.

The sixth Sonata is a little less emphatic in its harmonic foundation than the seventh. Its opening subject, for instance :

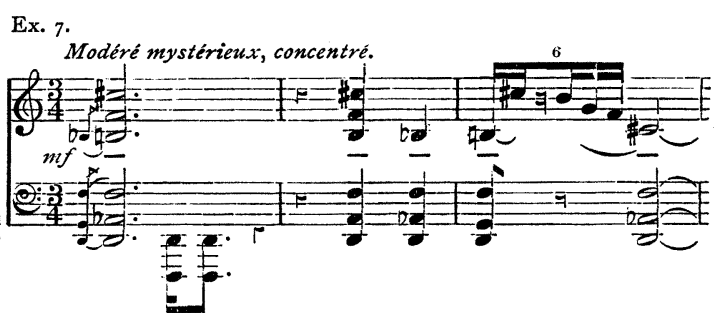

although definitely built on the harmonies evolved from the scale (Ex. 3), plays with lengthened appoggiatura (concerned with the insistence of the $B$ and A flat), while the second essential of the double pedal, G-D, provides a curious foundation. It might be stated at once that the flattened fifth in this chord of the thirteenth (the actual thirteenth is absent, of course, in this opening) is frequently to be found in association with the natural fifth which, theoretically, it should displace. This effect is to be found frequently in modern French music, i.e. :

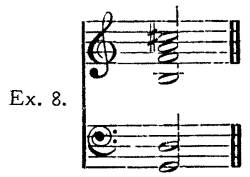

The C sharp, of course, is D flat, and the notation is only for convenience.

The idea of Ex. 7 is persisted in for eight bars, when a brief transposition :

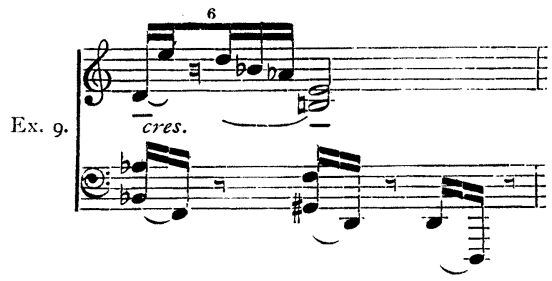

leads immediately to a melodic motto-phrase, which, with many varieties of treatment, recurs insistently with a curious exotic charm throughout the work :

Ex. о.

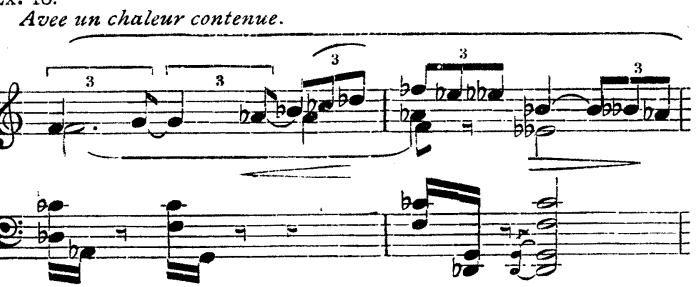

It will be noticed how two distinct dominants, $G$ and $D$ h, control this phrase : the melody itself is built on the scale, Ex. 3, and in the second bar the essence of the harmonic construction of the seventh Sonata receives a timid statement in the chords :

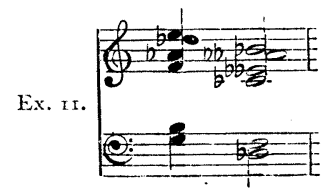


both thirteenths; and it might be here pointed out that Scriabine, as in these examples, always omits the eleventh. Its close approximation to the third and flattened fifth, even in distribution, would in its use certainly result in some trying tests to the ear. The effect of the seventh and thirteenth together is probably sufficient for the composer at the moment, but logically he is entitled to hold the other up his sleeve for some future occasion.

Exx. 7, 9, and 10, with an appendix to ro: Ex. 12.

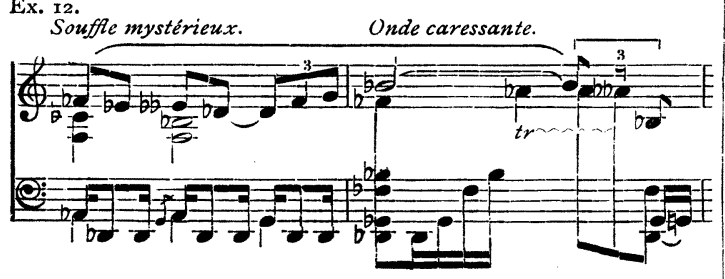

and the following clear and significant melody

Le rêve prend forme.
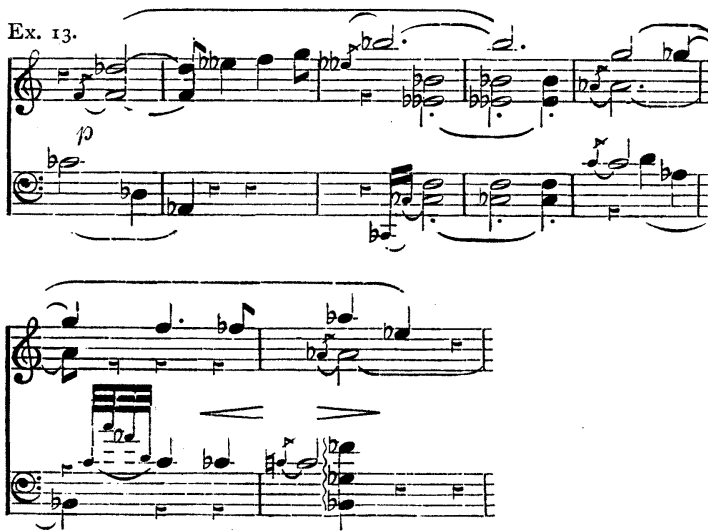

followed by the undulating figure in Ex. I 2, with an inner part of which, later on, significant use is made :

Ex. I.

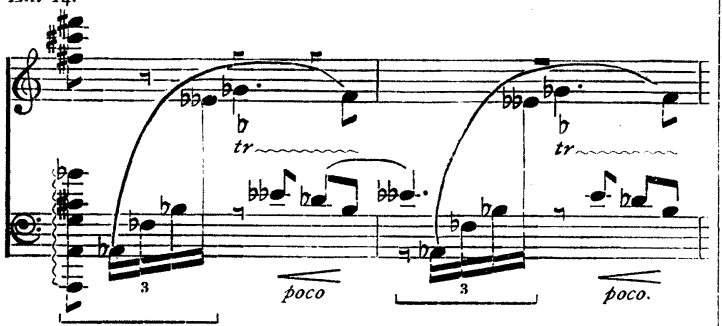

provide the material of the principal subject of the Sonata. A movement that might be taken as a second subject is, in its harmonic contents, a consistent and persistent exposition of the scale, Ex. 3 :

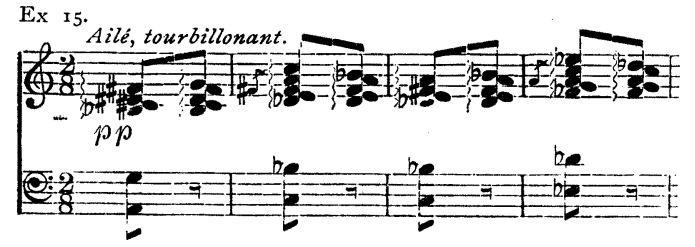

prepared by the following scintillating passages based on the final five notes:
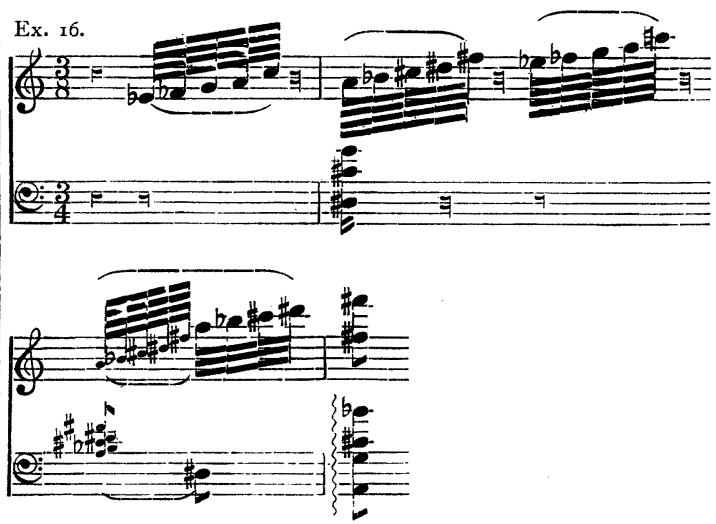

Shortly after, a moment arrives when a new arrangement of its constituents appears to relieve the chord entirely of its dominant character :

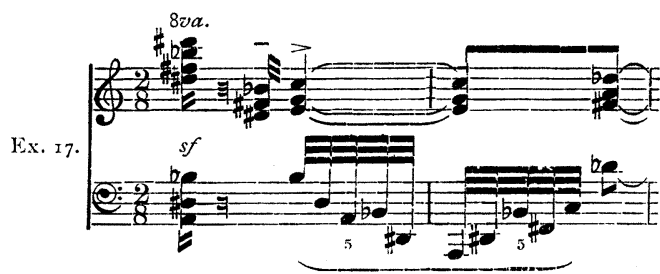

(To be continued.)

\section{Occasional motes.}

The ancient controversy as to the proper solmisation of the minor mode has been recently revived. Should the minor tonic and all its other scale-degree relations be sol-faed just as they are in the major key, or should they be named as a mode of a key, and, therefore, from the lah, or sixth of the major key? That is, should the nomenclature be-

Major: doh ray me fah soh lah te doh' Minor: doh ray ma fah soh la te doh' or,

Minor: $\mathrm{lah}_{1}$ te, doh ray me fah se lah

Musicians not concerned in elementary teaching and doctrine will no doubt be disposed to exclaim :

'Why should all this difference be

'Twixt tweedledum and tweedledee?'

But to many thousands of school teachers in English speaking countries the question is a really important one. It is not a matter of choice between tonic sol-fa notation and staff notation. It affects all the 'Movable Dohists' who apply the sol-fa syllables to the staff. As to the tonic sol-fa notation itself the rigorous adoption of the 'Doh minor' plan would practically rule it out of existence. We cannot here enter into the full details of the arguments on both sides. They are all to be found in pamphlets issued years ago. It may be admitted that all the logic appears to be (but is not 